\title{
Government intervention in municipal waste collection with a sustainable approach: a robust bi-level problem
}

\author{
Afrouz Rahmandoust ${ }^{1} \cdot$ Ashkan Hafezalkotob $^{2}$ (D) $\cdot$ Bijan Rahmani Parchikolaei $^{3}$. \\ Amir azizi ${ }^{4}$
}

Received: 6 July 2021 / Accepted: 1 February 2022 / Published online: 23 February 2022

(c) The Author(s), under exclusive licence to Springer Nature B.V. 2022

\begin{abstract}
Conservation of the environment has taken a prime position among areas of concern for managers and practitioners worldwide. This study aims to provide a bi-level mathematical model for municipal waste collection considering the sustainability approach. The mathematical model with conflicting objects was proposed at the upper level of the model of maximizing government revenue from waste recycling and at the lower level of minimizing waste collection and recycling costs, which had stochastic parameters and was scenario based. A case study was conducted in the Saveh processing site (Iran). Due to the complexity of the bi-level model, the KKT approach was adopted to unify the model. Finally, the relevant calculations were performed based on actual information. The results of the problem in the case study showed the efficiency of the proposed method. Several computational analyses randomly generated different waste recycling rates and obtained significant management results.
\end{abstract}

Keywords Municipal waste $\cdot$ Collection $\cdot$ Routing $\cdot$ Time window $\cdot$ Revenue

Ashkan Hafezalkotob

a_hafez@azad.ac.ir; ashkan.hafez@gmail.com

Afrouz Rahmandoust

afrouz2014@gmail.com; rahmandoust_a@hotmail.com

Bijan Rahmani Parchikolaei

bijanrah40@gmail.com

Amir azizi

azizi@srbiau.ac.ir

1 Science and Research Branch, University Square, Industrial Engineering College, Islamic Azad University, Sattari Highway, Shohada Hesarak blvd, 1477893855 Tehran, Iran

2 South Tehran Branch, Industrial Engineering College, Islamic Azad University, Entezari Alley, Oskoui Alley, Choobi Bridge, 1151863411 Tehran, Iran

3 Department of Mathematics, Nour Branch, Islamic Azad University, 4641859557 Nour, Iran

4 Faculty Member of Industrial Engineering Department, Science and Research Branch, Islamic Azad University, University Square, Sattari Highway, 1477893855 Tehran, Iran 


\section{Introduction}

Municipal solid waste (MSW) is a significant cause of climate change and global warming (Babaee Tirkolaee et al., 2018; Son \& Louati, 2016). Today, a serious challenge faced by cities, especially metropolises, is the issue of waste and its correct and principled management. As such, the management of waste production, storage, transportation, processing, and disposal is of utmost importance, and any negligence in proper management will cause irreparable damage (Jorge et al., 2021; Manaf et al., 2009; Bing et al., 2014). The volume of MSW in many developing countries such as China, Brazil, and India shows a steady increase, known as the waste siege challenge, due to its importance (Boskovic et al., 2016). One way to tackle the steady increase in MSW is to ensure that it is collected and engineered as fully as possible (Ribeiro et al., 2018). Meanwhile, the private sector can significantly contribute to urban waste management (Salazar-Adams, 2021). Of all the stages of waste management, waste collection from the waste generation center to the waste management center, i.e., the waste collection route, is a highly critical issue (Jaunich et al., 2016; Richter et al., 2018; Sanjeevi \& Shahabudeen, 2016). Optimal routing can help reduce costs and fuel consumption (González et al., 2021). Waste collection is part of the process of discharging recyclable waste (solid waste and recyclable goods) collected from a set of points (trash) and disposed of in a recycling center (a recycling plant, an energy recovery center, or waste disposal) (Valizadeh, 2020). In such cases, disposal centers are often only one destination, and this is a reverse logistics problem (RLP), i.e., collecting from several points (trash) and delivering to only one point (as opposed to delivering from one point to several destinations, which is a matter of advanced logistics problems (FLP)). A significant point in these problems is vehicle routing (Hannan et al., 2018). The collection of municipal waste accounts for $80 \%$ of waste management costs. Therefore, a slight improvement in municipal waste collection operations can significantly affect cost savings (Budzianowski, 2012). With the presence of animals, rodents, and pests, failure to collect this waste in time can lead to infection and the spread of infectious diseases (Pérez-López et al., 2016; Zhang \& Huang, 2014).

Recently, great emphasis has been placed on sustainability integration (Ahi \& Searcy, 2013), and all governments are striving for economic, environmental, and social sustainable development (Tseng et al., 2018). As with other activities, the municipal waste collection considers social and environmental impacts and economic and financial outcomes significant for maintaining sustainability (Abdel-Basset et al., 2020). Governments can assist the principled management of municipal waste by enacting certain policies (Valizadeh, Aghdamigargari, et al., 2021; Valizadeh, Aickelin, et al., 2021; Valizadeh, Mozafari, et al., 2021; Valizadeh, Sayed Alizadeh, et al., 2021). Herein, we show how government decisions on municipal waste management will help collect, recycle, and dispose of municipal waste. By considering government intervention, we model the process of collecting, recycling, and disposing of municipal waste. In addition to increasing government revenue from waste recycling, we minimize the total costs associated with collecting MSW. In addition, by considering government subsidies in exchange for MSW recycling, we encourage executive contractors and avoid wasting recyclable waste as much as possible. This article specifically addresses the following questions:

(1) To what extent can government intervention be effective in collecting and recycling municipal waste?

(2) How are different scenarios considered in the design of the waste collection problem? 
(3) How can various bi-level concerns of the MSW collection problem be considered in the form of a mathematical model?

Waste management has become a significant concern of governments (Valizadeh, Aghdamigargari, et al., 2021; Valizadeh, Aickelin, et al., 2021; Valizadeh, Mozafari, et al., 2021; Valizadeh, Sayed Alizadeh, et al., 2021), and waste recycling has significant economic and environmental benefits. Thus, this study mainly aims to provide a bi-level mathematical model for municipal waste collection considering the sustainability approach. We expect to achieve the following research objectives: (i) improving the MSW collecting system by a leader-follower approach, (ii) considering government intervention in supporting contractors based on subsidies for recycling wastes, (iii) considering government spending and total contractor costs in MSW collection in four probable scenarios, and (iv) establishing interactions between contractors collecting MSW and the government subsidy policies.

The remainder of this paper is organized as follows: A review of the literature is presented in Section 2. The prerequisites and assumptions are presented in Section 3. Section formulates the problem. Section 5 provides a numerical example and a desirable solution to reduce costs in the supply chain of polyethylene pipes. Analytical results and sensitivity analysis are also discussed. Final statements and some directions for future research are provided in Section 6.

\section{Literature review}

Here, the literature related to the research problem is reviewed in three subsections: (1) reviewing the research on municipal solid waste collection; (2) reporting the studies related to government involvement in the municipal waste collection; (3) presenting the research gap and contributions of the current study.

\subsection{Municipal solid waste collection}

Recently, urban waste management has become a significant concern of urban management, and considerable research has been conducted in this regard. Some researchers have tried to navigate based on the shortest distance (Hannan et al., 2018); other researchers have focused on finding a suitable place to store trash cans, bags, or bins (Bautista \& Pereira, 2006); and yet other studies have attempted to minimize the number of collection vehicles required for the harvesting system (Kuo et al., 2012). In general, research on the optimization of municipal waste collection can be classified into three categories: location-routing, location-allocation, and optimization of the collection process. Chalkias and Lasarid (2009) investigated the optimization of municipal solid waste collection using GIS in Athens and concluded that the proposed scenario for waste collection is worth adopting, both in fuel consumption and financial savings. According to Sbihi and Eglese (2010), waste management and collection are key treatments for protecting the environment and resources and fundamental processes in green logistics.

Markov et al. (2016) employed vehicle routing to collect waste and consider time in their research to collect waste from special containers in the city. After presenting a mathematical model for the problem, they optimized the problem on a small scale with a heuristic systematic local search algorithm and a neighborhood production algorithm. They concluded that optimizing for a small-scale problem would result in adequate cost savings. 
Hannan et al. (2018) conducted a study entitled Capacitive Routing Model for Solid Waste Collection and Path Optimization Using PSO Algorithm. The results obtained from different datasets showed that the proposed CVRP algorithm model yields the best waste collection and route optimization in terms of travel distance, total waste, waste collection efficiency, and coherence.

\subsection{Government involvement in municipal waste collection}

This section reviews the studies conducted on government involvement in waste collection and management. Cao et al. (2016) examined the role of government policies, businesses, and public awareness in improving e-waste recycling in China. They showed that with the efforts of the government, businesses, and citizens, the e-waste management in China improved and continued to develop from 2009 to 2015. Jin et al. (2020) studied the role of the government in compensating for the value of waste recycling in an industrial park. The proposed model, presented with a game theory approach, revealed that the compensatory value by the government increases with raising the waste recycling costs and environmental benefits and decreases with reducing the waste disposal and raw material costs. Valizadeh, Aghdamigargari, et al. (2021), Valizadeh, Aickelin, et al. (2021), Valizadeh, Sayed Alizadeh, et al. (2021), Valizadeh, Mozafari, et al. (2021)) proposed a bi-level model for collecting hazardous infectious waste and distributing sanitary items during the COVID19 pandemic, with the government as the leader at the top of the proposed model. They reported that government policies could help contractors during the pandemic. Table 1 reviews the research conducted on municipal waste management.

\section{Research gap and contributions}

Based on Table 1, studies show that waste collection is a key measure in the process of municipal waste management. Environmental issues are critical in urban waste management. To maintain environmental standards and prevent the loss of recyclable materials, we have attempted to maximize waste recycling in the proposed model. In addition to increasing government revenue, this will reduce the destructive effects of municipal waste disposal. Since waste collection costs account for the largest share of total waste management costs, an analysis of the waste collection process is necessary. The Saveh Municipality (Iran) is drawing up a contract with a mechanized contractor for each area, and according to its analysis, there is a need to review the analysis of routes and mechanized vehicles in that area. Accordingly, we proposed a model with the following innovations:

(a) We proposed a bi-level model for municipal waste collection. At the upper level of the model, the government as a leader tries to make the most of the collected waste by making specific decisions and enacting certain policies. We tried to maximize the upper level of the model by considering special government revenues from recycling. In other words, in the case of waste recycling, government revenue will be maximized by providing recycled materials (e.g., metals, paper, glass, and plastics).

(b) At the lower level, we considered the model of activities related to collecting and recycling municipal waste, which, in fact, follows governmental decisions. In fact, the executive contractors are motivated to receive the most government subsidies that are 


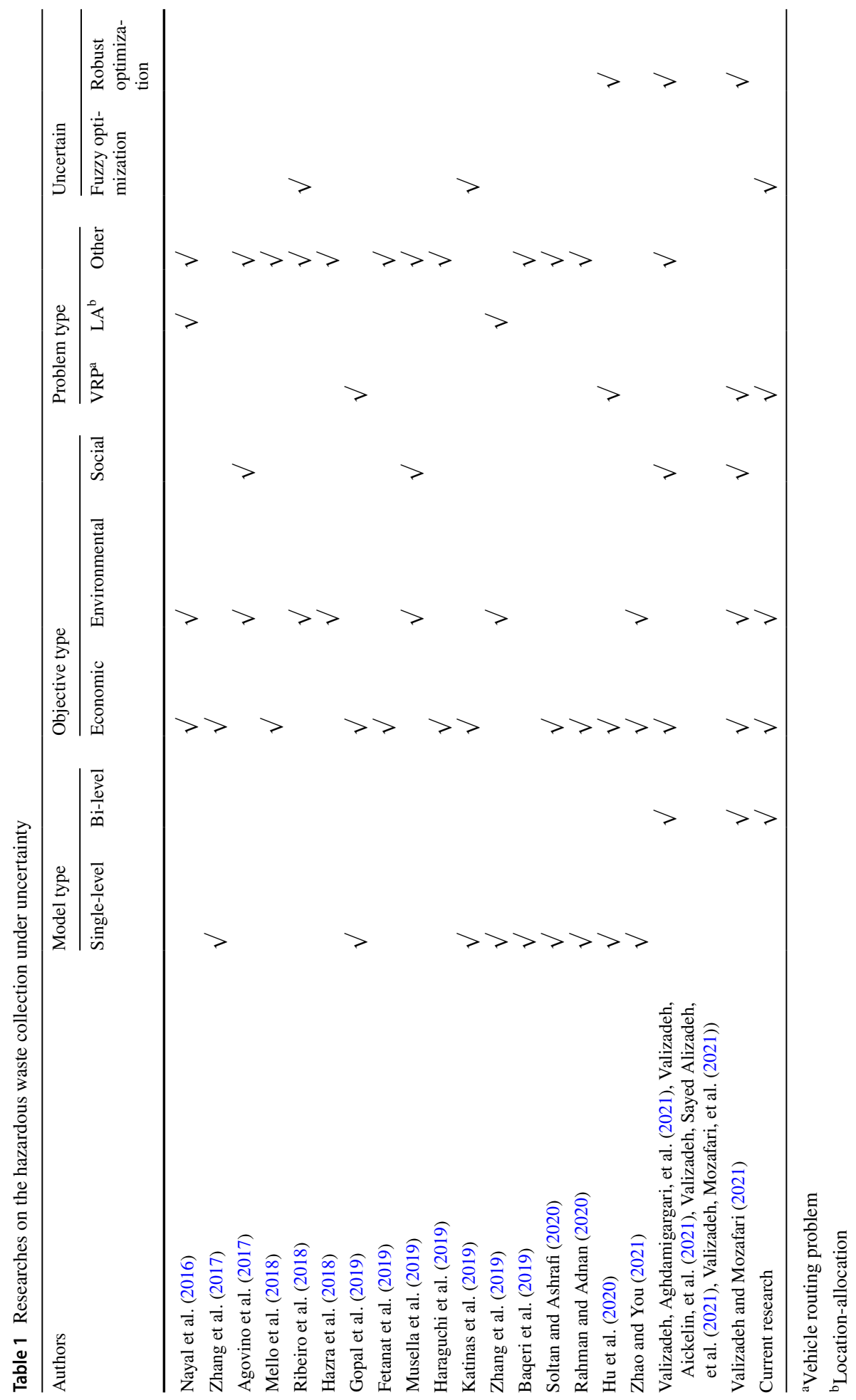


allocated to them in exchange for recycled waste. Government subsidies help contractors minimize waste collection and recycling costs.

(c) We have considered random parameters to deal with the existing uncertainty. Uncertainty in this study is the amount of waste recycling that depends on the recyclable materials collected. The bi-level model proposed by the KKT method becomes a singlelevel problem. Finally, the proposed model is evaluated as a case study with the data of Saveh.

\section{Research methodology}

The proposed model focuses on two levels of concern; its upper level aims to maximize government revenue, while its lower level focuses on the total contractor costs of municipal waste management. The reason for using a bi-level approach is to consider the concerns of two levels of stakeholders regarding waste management, where the upper level (as a leader) makes certain decisions and significantly affects the value of the program in the lower level. Therefore, considering the proposed model as a multi-objective may not achieve the desired results. Accordingly, by considering the three steps discussed below, the current study attempted to achieve the desired results for both levels of the problem by developing an efficient model.

Step 1 Like other mathematical optimization models, objective functions are formed by defining some indices and parameters and the existing variables. Accordingly, we consider some constraints for the model to imagine the expected optimal space.

Step 2 Due to the inherent uncertainty of optimization problems, we consider different scenarios for the amount of waste recycling at this step. Considering various uncertainties and scenarios will make the model reliable and yield optimal results in different situations. We include some scenarios with the probability of $\rho_{s}$ occurrence and, to limit the model in a stochastic state, we adopt Mulvey's approach.

Step 3 To solve the bi-level model, the model must first be converted into a singlelevel model. In this step, we use the KKT conditions to convert the model into a bi-level model. This method includes several constraints, including static constraints, initial problem constraints, dual problem constraints, and complementary deficiency constraints in the proposed model. The methodological structure of this research is displayed in Fig. 1.

\section{Problem description and formulation}

As mentioned in Section 1, there are several waste bins in place of citizens that must be emptied by vehicles with limited capacities. Due to the waste separation policy, municipal waste is classified into two categories of recyclable and unrecyclable wastes. After recycling, recyclable waste will be converted to a valuable commodity that will generate revenue for the government (leader). In the lower-level model, we attempt to minimize the costs of collection, transportation, and recycling. Therefore, through the model formulation of the problem, two main research objectives are pursued: (i) to propose an appropriate mathematical model for collecting MSW with government intervention, and (ii) to 


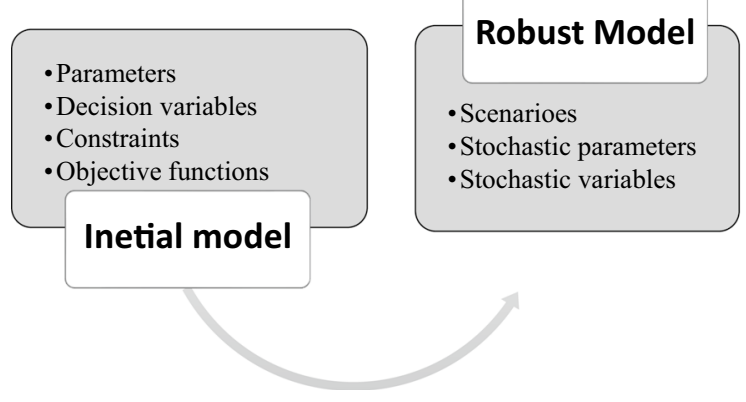

- Static restrictions

- The possible constraints of the original problem

- The possible constraints of the dual problem

- Additional deficiencies

\section{K.K.T conditions}

Fig. 1 Steps to perform mathematical modeling

establish interactions between contractors collecting MSW and government subsidy policies. The general scheme of the model is depicted in Fig. 2.

To model the problem, the following assumptions are taken into account.

Assumption 1 Each vehicle, if selected, starts its journey from the warehouse and returns to the warehouse at the end of the trip. In other words, no vehicle is allowed to start from a location other than the processing center. However, the unloading vehicles are only allowed in processing centers (Aydemir-Karadag, 2018; Hannan et al., 2018). This assumption

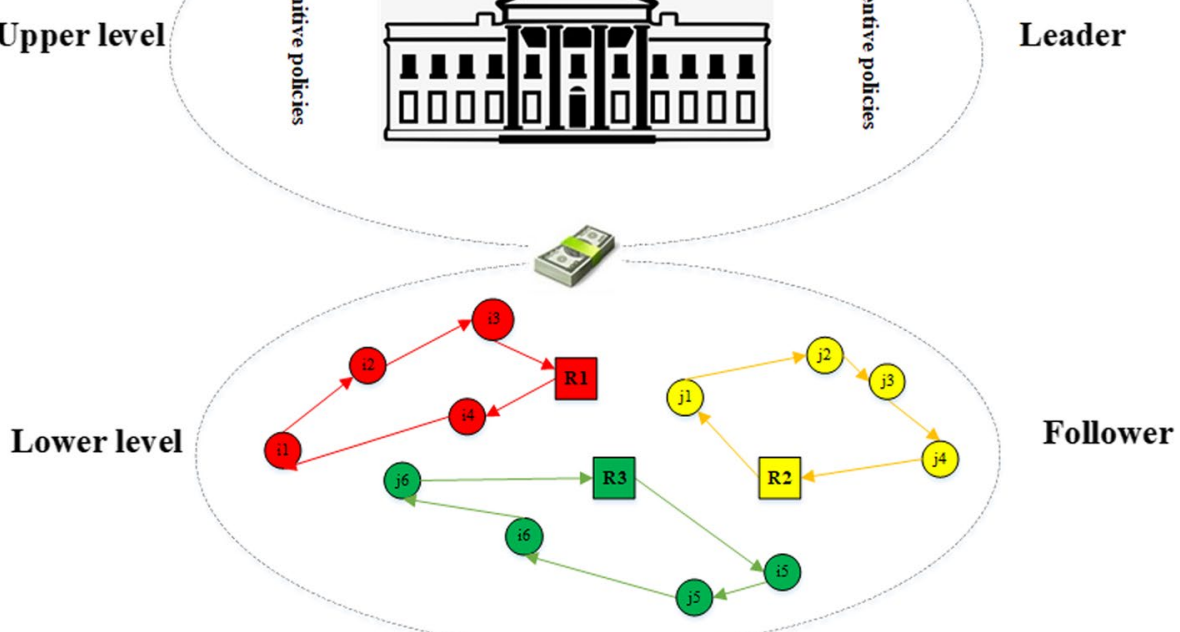

Fig. 2 The bi-level model of waste collection 
prevents the creation of subnets and prevents the proposed model from being trapped in the local optimal space.

Assumption 2 Full service to all nodes is provided on the first visit of that node. In other words, the vehicles collect the available waste at the first visit to each level of waste. No vehicle is allowed to travel to the trash more than once (Hannan et al., 2018). This assumption helps avoid duplicate loops in the problem. Moreover, as the waste bin is emptied on the first visit and it takes some time to refill it, this assumption approximates the problem to the real world.

Assumption 3 Vehicles have limited capacity. In other words, whenever a vehicle moves from the processing center, it is considered current capacity. Similarly, it is assumed that vehicles will return to processing centers when their capacity is full. The vehicle is allowed to return to the processing center at any capacity level only when the number of unvisited waste bins is zero (Aydemir-Karadag, 2018; Valizadeh, Aghdamigargari, et al., 2021; Valizadeh, Aickelin, et al., 2021; Valizadeh, Mozafari, et al., 2021; Valizadeh, Sayed Alizadeh, et al., 2021). This assumption helps ensure that no trash is left in the city and all the bins are visited at least once by the vehicles.

In the proposed model, a number of vehicles $v$ and a number of people (sweepers) are considered to collect municipal waste $w$ from points $(i)$ and $(j)$. In fact, points $(i)$ and $(j)$ represent the waste bins located at the start and end of the route, respectively; vehicles must visit the designated points at least once to collect municipal wastefully. The collected waste is transferred to processing centers $(r)$ after collection. After processing the collected waste, the recyclable waste is transferred to recycling centers $(k)$ and recycled there. Now, to formulate the mathematical model, we must first introduce the mathematical indexes related to it and then explain the mathematical model.
$i, j \quad$ Index of points index (waste bin).
$v$ Index of vehicle.
$c \quad$ Index of people.
$w$ Index of municipal waste.
$r \quad$ Index of processing centers.
$k \quad$ Index of recycling centers.
$M \quad$ A large number.

\subsection{Problem parameters}

After specifying the model indices, it is time to determine the parameters, these parameters are:

$c r_{w v i r} \quad$ The cost of transporting each unit of waste $w$ by vehicle $v$ from point $i$ to point $r$

$c k_{w v r k} \quad$ The cost of transporting each unit of waste $w$ by vehicle $v$ from point $r$ to point $k$

$c h_{k w} \quad$ Cost of waste recycling $w$ by recycling center $k$

$g r_{w} \quad$ Government subsidy for recycling each unit of waste $w$

$g p_{w} \quad$ Government profit from waste recycling $w$

$d_{i j r k} \quad$ Distance between points $i, j, r, k$.

$w g_{k w} \quad$ Waste weight $w$ transported to the recycling center $k$ 
$q_{w} \quad$ Estimated amount of recycled waste $w$

$r e_{k w} \quad$ The rate set for waste recycling $w$ by recycling center $k$ (This rate is actually a fraction of the amount of waste recycled over the amount of waste collected. This rate is a number between zero and one, and the closer it is to one, will be better).

$p_{v} \quad$ Vehicle capacity $v$

\subsection{Problem variables}

According to the purpose of the problem, we must determine the model variables, which are:

$X_{v i j r} \quad$ If vehicle $v$ passes through the edge $(i, j)$ or $(i, \mathrm{r})$ or $(j, r)$, its value is 1 and otherwise equal to 0.

$Y_{v k r} \quad$ If vehicle $v$ crosses the $\operatorname{rim}(k, r)$, its value is 1 , otherwise it is equal to 0 .

$Z_{k w}$ If the recycling center k recycles waste $w$, its value is 1 and otherwise it is equal to 0 .

$E_{i v} \quad$ If the point $i$ th is the last node that the $v$ vehicle serves, its value is 1 and otherwise it is equal to 0 .

$U_{k w} \quad$ Recycling capacity of center $k$ for waste recycling $w$. Due to the rising trend of waste generation caused by urban developments and population growth, the management of municipal waste is the best policy. To this end, governments have adopted various policies for waste recycling, such as enhancing municipal waste recycling to support contractors and encourage them to recycle more. Given the value of municipal waste and the possibility of recycling it, we tried to simultaneously address the concerns of the government and contractors collecting municipal waste. To this end, a bi-level mathematical model is proposed that simultaneously considers the government's profits and contractors' costs. In other words, by formulating the problem model, two main goals are pursued: (i) to increase government profits by increasing municipal waste recycling, and (ii) to reduce the cost of collecting and recycling municipal waste by choosing the optimal route and receiving government subsidies. In this study, the unit of waste is kilograms, and the unit of all costs is dollars.

\subsection{Upper-level model}

$$
\begin{gathered}
\operatorname{Max} Z 1=\sum_{w \in W} \sum_{k \in K} g p_{w} w g_{k w} r e_{k w} U_{k w}-\sum_{w \in W} \sum_{k \in K} g r_{w} q_{w} Z_{k w} \\
\sum_{w \in W} U_{k w} \leq \sum_{v \in V} \sum_{r \in S} y_{v k r} \quad \forall k \in K \\
Y_{v k r}, Z_{k w} \in(0,1) \quad \forall k \in K, w \in W \\
q_{w}, U_{k w} \geq 0 \quad \forall k \in K, w \in W .
\end{gathered}
$$

Equation (1) is related to the upper-level objective function, which seeks to maximize the amount of recycled waste and government profits. The first part shows the total government's revenue from waste recycling. The second part demonstrates the total subsidy paid by the government to the contractor. Herein, government subsidies include cash subsidies 
paid to contractors per unit of recycled municipal waste. Constraint (2) denotes the recycling centers' capacity limit, and Constraints (3) and (4) indicate the type of problem variables.

\subsection{Lower-level model}

$$
\begin{aligned}
& \operatorname{Min} Z 2=\sum_{(i, j) \in N} \sum_{v \in V} \sum_{w \in W} \sum_{r \in S} X_{v i j r} c r_{w v i r} d_{i j r k}+\sum_{(i, j) \in N} \sum_{v \in V} \sum_{w \in W} \sum_{k \in K} \sum_{r \in R} Y_{v k r} c k_{w v r k} d_{i j r k}+\sum_{w \in W} \sum_{k \in K} Z_{k w} c h_{k w} q_{w} \\
& \sum_{v \in V} \sum_{r \in R} X_{v 0 j r}=0 \quad \forall j \in N \\
& \sum_{v \in V} Y_{v k 0}=0 \quad \forall k \in K \\
& \sum_{r \in R} \sum_{v \in V} X_{v i j r}-\sum_{r \in R} \sum_{v \in V} X_{v j i r}=0 \quad \forall(i, j) \in N \\
& \sum_{(i, j) \in N} \sum_{v \in V} X_{v i j r}+\sum_{k \in K} \sum_{v \in V} Y_{v k r}=1 \quad \forall r \in R \\
& \sum_{w \in W} Z_{k w} \geq 1 \quad \forall k \in K \\
& \sum_{v \in V} E_{i v}+p_{v j i}=p_{v i j} \quad \forall(i, j) \in N \\
& \sum_{(i, j) \in N} X_{v i j r} \geq \sum_{k \in K} Y_{v k r} \quad \forall v \in V, r \in R \\
& \sum_{v \in V} \sum_{r \in R} Y_{v k r} \geq \sum_{w \in W} Z_{k w} \quad \forall k \in K \\
& \sum_{v \in V} \sum_{r \in R} q_{w} Y_{v k r} \leq \sum_{w \in W} U_{k w} Z_{k w} \quad \forall k \in K, w \in W \\
& X_{v i j r}, E_{i v} \in(0,1) \quad \forall(i, j) \in N, r \in R, v \in V \\
& d_{i j r} \geq 0 \quad \forall(i, j) \in N, r \in R .
\end{aligned}
$$

Equation (5) relates to the lower-level objective function, which seeks to minimize the cost of waste collection and recycling by the contractor. The first part shows the total cost of transporting waste from the trash to the processing centers by vehicles; the second part demonstrates the total costs of transporting waste from processing centers to recycling centers by vehicles, and the third part represents the total waste recycling costs. As mentioned above, the objective function minimizes all of these costs. Constraints (6) and (7) indicate that the 
collection of all municipal waste must be done by vehicles. If the left side of Constraints (6) and (7) is $>1$, the recycled waste is collected by the vehicles. Constraints (8) and (9) ensure chain continuity. Constraint (10) guarantees that waste is recycled for at least one shipment of the collected waste. Constraint (11) ensures that if the vehicle's capacity is full, it is the collection point for the vehicle. Constraint (12) shows that the waste shipped from processing centers is not more than the waste collected. Constraint (13) ensures that recycled waste does not exceed the waste shipped from the recycled centers. Constraint (14) expresses the capacity limit of recycling centers. Finally, Constraints (15) and (16) denote the type of problem variables.

There are two categories of variables in uncertainty models: design or scenario-independent variables and control or scenario-dependent variables. The values of scenarioindependent variables are not affected by different scenarios and remain the same in the model. On the other hand, different scenarios affect control or scenario-dependent variables, and their values change across scenarios. Constraints are also divided into two categories of structural and control constraints; structural constraints are scenario and uncertainty independent, whereas control constraints are scenario dependent. In fact, the robust optimization between the optimal model solution and model feasibility provides a weighting style to the decision-maker.

A robust optimization model for a mathematical programming problem can be represented as:

$$
\begin{gathered}
\operatorname{Min} Z=\sigma\left(x, y_{1}, y_{2}, \ldots, y_{s}\right)+\omega \rho\left(\delta_{1}, \delta_{2}, \ldots, \delta_{s}\right) \\
W x=b \\
B_{s} x+C_{s} y_{s}+\delta_{s}=e_{s} \quad \forall s \in \Omega \\
x \geq 0, y_{s} \geq 0 \quad \forall s \in \Omega .
\end{gathered}
$$

The variable $x$ in this model is a design- or scenario-independent variable, and Constraint (19) is a structural constraint. The variable $y_{s}$ is a control or scenario-dependent variable, and Constraint (20) is a control constraint. The parameters $\left\{B_{s}, C_{s}, e_{s}\right\}$ are scenario-affected parameters. Moreover, the error vector $\delta_{s}$ shows the incommensurability of the control constraints under different scenarios (Tavanayi et al., 2020). The first part of the objective function is related to a robust solution, which evaluates the closest optimal answer for all scenarios (Jabbarzadeh et al., 2014). The second part of the objective function is the criterion of model stability, which is related to model feasibility for almost all possible scenarios. In other words, it imposes control restrictions under some scenarios in case of exceeding the model's area (Valizadeh, Aghdamigargari, et al., 2021; Valizadeh, Aickelin, et al., 2021; Valizadeh, Mozafari, et al., 2021; Valizadeh, Sayed Alizadeh, et al., 2021). Moreover, $\omega$ is defined as the risk aversion factor, indicating a weighting between model optimality and feasibility. For example, if $\omega$ is zero, the answer will likely be unmodulated and out of the solution space of the model. If this coefficient is high, although it maintains the model's ability for different scenarios, it increases costs (Akbari et al., 2021). Mulvey et al. (1995) provided an appropriate definition for $\sigma\left(X, Y_{1}, Y_{2}, \ldots, Y_{s}\right)$ as follows:

$$
\sigma\left(x, y_{1}, y_{2}, \ldots, y_{s}\right)=\sum_{s \in \Omega} P_{s} \xi_{s}+\lambda \sum_{s \in \Omega} P_{s}\left(\xi_{s}-\sum_{\substack{\prime \\ s \in \Omega}} P_{s^{\prime}} \xi_{s^{\prime}}\right) .
$$


The coefficient of variability $\lambda$ is the objective function's degree of sensitivity to changes in the input data under different scenarios, and by increasing $\lambda$, this variability (variance) decreases. (Valizadeh, Aghdamigargari, et al., 2021; Valizadeh, Aickelin, et al., 2021; Valizadeh, Mozafari, et al., 2021; Valizadeh, Sayed Alizadeh, et al., 2021). Moreover, $\rho\left(\delta_{1}, \delta_{2}, \ldots, \delta_{s}\right)$ is defined as:

$$
\rho\left(\delta_{1}, \delta_{2}, \ldots, \delta_{s}\right)=\sum_{s \in \Omega} P_{s} \delta_{s}
$$

As a result, the objective function of the model can be reworded as follows:

$$
\operatorname{Min} Z=\sum_{s \in \Omega} P_{s} \xi_{s}+\lambda \sum_{s \in \Omega} P_{s}\left(\xi_{s}-\sum_{\substack{\prime \\ s \in \Omega}} P_{s^{\prime}} \xi_{s^{\prime}}\right)+\sum_{s \in \Omega} P_{s} \delta_{s}
$$

The model has been re-modeled in the state of uncertainty with robust optimization and using Mulvey et al. (1995) approach, as follows:

$\rho_{s} \quad$ Probability of occurrence of any scenario.

$q_{w}^{s} \quad$ Estimated amount of waste recycling $w$ under scenario $s$.

$\lambda$ The coefficient of the significance of variability.

$\omega$ The coefficient of the significance of the model.

According to the purpose of the problem, we must determine the model variables, which are:

$X_{v i j r}^{s} \quad$ If under scenario $s$ vehicle $v$ passes through the edge $(i, j)$ or $(i, r)$ or $(j, r)$, its value is 1 ; otherwise, it is 0 .

$Y_{v k r}^{s} \quad$ If under scenario $s$ vehicle $v$ passes through the edge $(k, r)$, its value is 1 ; otherwise, it is 0 .

$Z_{k w}^{s} \quad$ If under scenario $s$ the recycling center $k$ recycles waste $\mathrm{w}$, its value is 1 ; otherwise, it is 0 .

$E_{i v}^{s} \quad$ If under scenario $s$ point $i$ is the last node served by vehicle $v$, its value is 1 ; otherwise, it is 0 .

$\theta_{s}, \theta_{s}^{\prime} \quad$ Deviation variables of the objective functions.

$\delta_{k s} \quad$ Variable of control constraint violation.

Considering the scenarios, we reformulate the mathematical model as follows:

$$
\begin{aligned}
\operatorname{Min} Z 1= & \sum_{w \in W} \sum_{k \in K} g p_{w} w g_{k w} r e_{k w} U_{k w}-\sum_{w \in W} \sum_{k \in K} \sum_{s \in S} \rho_{s} g r_{w} q_{w}^{s} Z_{k w}^{s} \\
& +\lambda \sum_{s \in S} \rho_{s}\left(\sum_{w \in W} \sum_{k \in K} g r_{w} q_{w}^{s} Z_{k w}^{s}-\sum_{w \in W} \sum_{k \in K} \sum_{s^{\prime} \in S} \rho_{s} g r_{w} q_{w}^{s^{\prime}} Z_{k w}^{s^{\prime}}+2 \theta_{s}\right) \\
& \left(\sum_{w \in W} \sum_{k \in K} \sum_{s \in S} g r_{w} q_{w}^{s} Z_{k w}^{s}-\sum_{w \in W} \sum_{k \in K} \sum_{s^{\prime} \in S} \rho_{s} g r_{w} q_{w}^{s^{\prime}} Z_{k w}^{s^{\prime}}+\theta_{s}\right) \geq 0 \quad \forall s \in S
\end{aligned}
$$




$$
\begin{gathered}
\sum_{w \in W} U_{k w} \leq \sum_{v \in V} \sum_{r \in R} \sum_{s \in S} Y_{v k r}^{s} \quad \forall k \in K \\
Y_{v k r}^{s}, Z_{k w}^{s} \in(0,1) \quad \forall k \in K, w \in W, \quad s \in S \\
q_{w}^{s}, U_{k w}, \theta_{s} \geq 0 \quad \forall k \in K, w \in W, \quad s \in S
\end{gathered}
$$

$$
\begin{aligned}
\text { Min } Z 2= & \sum_{(i, j) \in N} \sum_{v \in V} \sum_{w \in W} \sum_{r \in R} \sum_{s \in S} \rho_{s} X_{v i j r}^{s} c r_{w v i r} d_{i j r k} \\
& +\sum_{(i, j) \in N} \sum_{v \in V} \sum_{w \in W} \sum_{r \in R} \sum_{k \in K} \sum_{s \in S} \rho_{s} Y_{v k r}^{s} c k_{w v r k} d_{i j r k} \\
& +\sum_{k \in K} \sum_{w \in W} \sum_{s \in S} \rho_{s} Z_{k w}^{s} c h_{k w} q_{w}^{s} \\
& +\lambda \sum_{s \in S} \rho_{s}\left(\sum_{(i, j) \in N} \sum_{v \in V} \sum_{w \in W} \sum_{r \in R} X_{v i j r}^{s} c r_{w v i r} d_{i j r k}\right. \\
& +\sum_{(i, j) \in N} \sum_{v \in V} \sum_{w \in W} \sum_{r \in R} \sum_{k \in K} Y_{v k r}^{s} c k_{w v r k} d_{i j r k}+\sum_{k \in K} \sum_{w \in W} Z_{k w}^{s} c h \\
& -\sum_{(i, j) \in N} \sum_{v \in V} \sum_{w \in W} \sum_{r \in R} X_{v i j r}^{s} c r_{w v i r} d_{i j r k} \\
& +\sum_{(i, j) \in N} \sum_{v \in V} \sum_{w \in W} \sum_{r \in R} \sum_{k \in K} Y_{v k r}^{s} c k_{w v r k} d_{i j r k} \\
& \left.+\sum_{k \in K} \sum_{w \in W} Z_{k w}^{s} c h\right)+\omega \sum_{s \in S} \sum_{k \in K} \rho_{s} \delta_{k s}
\end{aligned}
$$

$$
\begin{aligned}
& \left(\sum_{(i, j) \in N} \sum_{v \in V} \sum_{w \in W} \sum_{r \in R} X_{v i j r}^{s} c c_{w v i r} d_{j i j k}+\sum_{(i, j) \in N} \sum_{v \in V} \sum_{w \in W} \sum_{r \in R} \sum_{k \in K} Y_{v k r}^{s} c c_{w v r k} d_{i j r k}+\sum_{k \in K} \sum_{w \in W} Z_{k w}^{s} c c_{k w} q_{w}^{s}\right.
\end{aligned}
$$

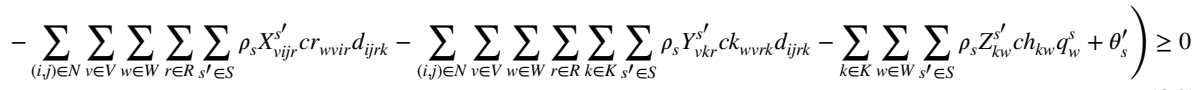

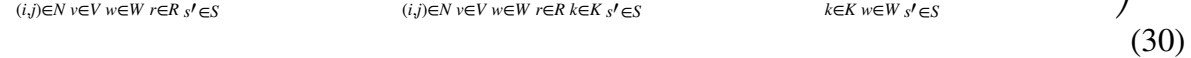

$$
\begin{gathered}
\sum_{v \in V} \sum_{r \in R} X_{v 0 j r}^{s}=0 ; \quad \forall j \in N, s \in S \\
\sum_{v \in V} Y_{v k r}^{s}=0 ; \quad \forall k \in K, s \in S \\
\sum_{r \in R} \sum_{v \in V} X_{v i j r}^{s}-\sum_{r \in R} \sum_{v \in V} X_{v j i r}^{s}=0 ; \quad \forall(i, j) \in N, s \in S \\
\sum_{(i, j) \in N} \sum_{v \in V} X_{v i j r}^{s}+\sum_{k \in K} \sum_{v \in V} Y_{v k r}^{s}=1 ; \quad \forall r \in R, s \in S
\end{gathered}
$$




$$
\begin{gathered}
\sum_{w \in W} Z_{k w}^{s} \geq 1 ; \quad \forall k \in K, s \in S \\
\sum_{v \in V} \sum_{s \in S} E_{i v}^{s}+p_{v j i}=p_{v i j} ; \quad \forall(i, j) \in N, s \in S \\
\sum_{(i, j) \in N} X_{v i j r}^{s} \geq \sum_{k \in K} Y_{v k r}^{s} ; \quad \forall v \in V, r \in R, s \in S \\
\sum_{v \in V} \sum_{r \in R} Y_{v k r}^{s} \geq \sum_{w \in W} Z_{k w}^{s} ; \quad \forall k \in K, s \in S \\
\sum_{v \in V} \sum_{r \in R} q_{w}^{s} Y_{v k r}^{s} \leq \sum_{w \in W} \sum_{s \in S} U_{k w} Z_{k w}^{s} ; \quad \forall k \in K, w \in W, s \in S \\
X_{v i j r}^{s}, E_{i v}^{s} \in(0,1) ; \quad \forall(i, j) \in N, r \in R, v \in V, s \in S \\
d_{i j r}, \theta_{s}^{\prime}, \delta_{k s} \geq 0 ; \quad \forall(i, j) \in N, r \in R, s \in S .
\end{gathered}
$$

It is well established in the literature that the optimal solution of bi-level optimization problems is a very complex process. This has been proven specifically for the simplest bilevel linear problem (Hansen et al., 1990). This is largely due to the fact that this is highly NP-hard research in the field of bi-level planning based on innovative and meta-innovative solution methods to achieve local optimization (Pouriani et al., 2019). In addition to these approaches, KKT conditions, which are the necessary and sufficient conditions for optimizing a lower-level problem, can convert the main problem into its single-level equivalent, allowing the solution to be solved by existing optimization programs. Herein, due to the problem of lower-level waste collection, we continued and easily rewrote it. Using the KKT condition with a lower-level model, the following four KKT conditions can be substituted to achieve a single-level problem:

\subsubsection{Static constraints}

These constraints are derived directly from the Lagrange function corresponding to the objective function of the lower-level problem. To form the Lagrange function, first, the constraints of the quadratic model in the robust optimization formula, i.e., Eqs. (6) to (14) and Eqs. (25) to (28) are written to the constraints in the form of $(0)$ or $(=0)$; then, the Lagrange coefficients or the double variables to the left of the rewritten constraints are multiplied. Finally, the sum of these multiplications and the lower-level objective function is calculated, which is equivalent to the Lagrange function of the lower-level problem. The Lagrange equation shows the lower-level problem in this research. 


$$
\begin{aligned}
& L(Y)=\sum_{(i, j) \in N} \sum_{v \in V} \sum_{w \in W} \sum_{r \in R} \sum_{s \in S} \rho_{s} X_{v i j r}^{s} c r_{w v i r} d_{i j r k}+\sum_{(i, j) \in N} \sum_{v \in V} \sum_{w \in W} \sum_{r \in R} \sum_{k \in K} \sum_{s \in S} \rho_{s} Y_{v k r}^{s} c k_{w v r k} d_{i j r k} \\
& +\sum_{k \in K} \sum_{w \in W} \sum_{s \in S} \rho_{s} Z_{k w}^{s} c h_{k w} q_{w}^{s}+\lambda \sum_{s \in S} \rho_{s}\left(\sum_{(i, j) \in N} \sum_{v \in V} \sum_{w \in W} \sum_{r \in R} X_{v i j r}^{s} c r_{w v i r} d_{i j r k}\right. \\
& +\sum_{(i, j) \in N} \sum_{v \in V} \sum_{w \in W} \sum_{r \in R} \sum_{k \in K} Y_{v k r}^{s} c k_{w v r k} d_{i j r k}+\sum_{k \in K} \sum_{w \in W} Z_{k w}^{s} c h_{k w} q_{w}^{s}-\sum_{(i, j) \in N} \sum_{v \in V} \sum_{w \in W} \sum_{r \in R} \sum_{s^{\prime} \in S} \rho_{s} X_{v i j r}^{s^{\prime}} c r_{w v i r} d_{i j r k} \\
& \left.-\sum_{(i, j) \in N} \sum_{v \in V} \sum_{w \in W} \sum_{r \in R} \sum_{k \in K} \sum_{s^{\prime} \in S} \rho_{s} Y_{v k r}^{S^{\prime}} c k_{w v r k} d_{i j r k}-\sum_{k \in K} \sum_{w \in W} \sum_{s^{\prime} \in S} \rho_{s} Z_{k w}^{s^{\prime}} c h_{k w} q_{w}^{s}+2 \theta_{s}^{\prime}\right)+\omega \sum_{s \in S} \sum_{k \in K} \rho_{s} \delta_{k s} \\
& -\sum_{j \in N} \sum_{s \in S} \pi_{j s}^{1}\left(\sum_{v \in V} \sum_{r \in R} X_{v 0 j r}^{s}\right) \\
& -\sum_{k \in K} \sum_{s \in S} \pi_{k s}^{2}\left(\sum_{v \in V} Y_{v k r}^{s}\right) \\
& -\sum_{(i, j) \in N} \sum_{s \in S} \pi_{i j s}^{3}\left(\sum_{r \in R} \sum_{v \in V} X_{v i j r}^{s}-\sum_{r \in R} \sum_{v \in V} X_{v j i r}^{s}\right) \\
& -\sum_{r \in R} \sum_{s \in S} \pi_{r s}^{4}\left(\left(\sum_{(i, j) \in N} \sum_{v \in V} X_{v i j r}^{s}+\sum_{k \in K} \sum_{v \in V} Y_{v k r}^{s}\right)-1\right) \\
& -\sum_{k \in K} \sum_{s \in S} \pi_{k s}^{5}\left(\sum_{w \in W} Z_{k w}^{s}-1\right) \\
& -\sum_{(i, j) \in N} \sum_{s \in S} \pi_{i j s}^{6}\left(p_{v i j}-\sum_{v \in V} \sum_{s \in S} E_{i v}^{s}+p_{v j i}\right) \\
& -\sum_{v \in V} \sum_{r \in R} \sum_{s \in S} \pi_{v r s}^{7}\left(\sum_{k \in K} Y_{v k r}^{s}-\sum_{(i, j) \in N} X_{v i j r}^{s}\right) \\
& -\sum_{k \in K} \sum_{s \in S} \pi_{k s}^{8}\left(\sum_{w \in W} Z_{k w}^{s}-\sum_{v \in V} \sum_{r \in R} Y_{v k r}^{s}\right)
\end{aligned}
$$




$$
\begin{aligned}
-\sum_{s \in S} \pi_{s}^{9} & \left(\sum_{(i, j) \in N} \sum_{v \in V} \sum_{w \in W} \sum_{r \in R} X_{v i j r}^{s} c r_{w v i r} d_{i j r k}+\sum_{(i, j) \in N} \sum_{v \in V} \sum_{w \in W} \sum_{r \in R} \sum_{k \in K} Y_{v k r}^{s} c k_{w v r k} d_{i j r k}\right. \\
& +\sum_{k \in K} \sum_{w \in W} Z_{k w}^{s} c h_{k w} q_{w}^{s}-\sum_{(i, j) \in N} \sum_{v \in V} \sum_{w \in W} \sum_{r \in R} \sum_{s^{\prime} \in S} \rho_{s} X_{v i j r}^{s^{\prime}} c r_{w v i r} d_{i j r k} \\
& \left.-\sum_{(i, j) \in N} \sum_{v \in V} \sum_{w \in W} \sum_{r \in R} \sum_{k \in K} \sum_{s^{\prime} \in S} \rho_{s} Y_{v k r}^{s^{\prime}} c k_{w v r k} d_{i j r k}-\sum_{k \in K} \sum_{w \in W} \sum_{s^{\prime} \in S} \rho_{s} Z_{k w}^{s^{\prime}} c h_{k w} q_{w}^{s}+\theta_{s}^{\prime}\right) \\
& -\sum_{k \in K} \sum_{w \in W} \sum_{s \in S} \pi_{k w s}^{10}\left(\sum_{w \in W} \sum_{s \in S} U_{k w} Z_{k w}^{s}-\sum_{v \in V} \sum_{r \in R} q_{w}^{s} Y_{v k r}^{s}+\delta_{k s}\right) \\
-\sum_{s \in S} \pi_{s}^{11}\left(\theta_{s}^{\prime}\right) & -\sum_{k \in K} \sum_{s \in S} \pi_{k s}^{12}\left(\delta_{k s}\right)
\end{aligned}
$$

Under static constraints, the gradient of the Lagrange function relative to the lower-level decision-making variables is zero. Constraints (42) to (48) indicate the first-order KKT conditions.

$$
\begin{gathered}
\Psi_{i j s}-\pi_{k w s}^{10} q_{w}^{s}=0 ; \quad \forall i, j \in N, k \in K, w \in W, s \in S \\
\Psi_{i j s}-\pi_{k s}^{2}-\pi_{r s}^{4}+\pi_{v r s}^{7}-\pi_{k s}^{8}-\pi_{k w s}^{10} q_{w}^{s}=0 ; \quad \forall i, j \in N, k \in K, w \in W, s \in S \\
\Psi_{i j s}-\pi_{k w s}^{10} U_{k w}=0 ; \quad \forall i, j \in N, k \in K, w \in W, s \in S \\
\Psi_{i j s}+\pi_{k s}^{5}+\pi_{k s}^{8}=0 ; \quad \forall i, j \in N, k \in K, w \in W, s \in S \\
\Psi_{i j s}=\left(c k_{w v r k} d_{i j r k}+c h_{k w} q_{w}^{s}\right)\left(\rho_{s}\left(1+\lambda\left(1-\rho_{s}\right)\right)+\left(1-\rho_{s}\right) \pi_{s}^{9}\right) \\
\forall i, j \in N, k \in K, w \in W, r \in R, v \in V, s \in S \\
2 \lambda \rho_{s}-\pi_{s}^{9}-\pi_{s}^{11}=0 ; \quad \forall s \in S \\
\omega \rho_{s}-\pi_{k w s}^{10}-\pi_{k s}^{12}=0 ; \quad \forall k \in K, w \in W, s \in S .
\end{gathered}
$$

\subsubsection{The possible constraints of the original problem}

Constraints on the feasibility of the initial problem under KKT conditions indicate that the constraints of the upper-level problem must be established in the presence of the optimal value of decision variables and not violated. These constraints include Eqs. (6) to (14) and Eqs. (25) to (28). 


\subsubsection{The possible constraints of the dual problem}

Limitations of the feasibility of the dual problem in the KKT context state that the duality problem must remain feasible in return for the optimal answer. Accordingly, Lagrange coefficients corresponding to constraints greater than or equal to zero should be defined in the same way; for other constraints in the form of equations, their coefficients should be considered unconditionally in the model. Note that these coefficients are the same as the two problem variables.

\subsubsection{Supplementary deficiencies}

Supplementary deficiency conditions express the general relationship between the initial constraints and their corresponding Lagrange coefficients, wherein the product of the deficit variables in the initial constraints with their corresponding Lagrange coefficients is zero. Supplementary deficiency constraints pertaining to upper-level constraints are formulated as Constraints (49) to (60).

$$
\begin{gathered}
\pi_{j s}^{1}\left(\sum_{v \in V} \sum_{r \in R} X_{v 0 j r}^{s}\right)=0 ; \quad \forall j \in N, s \in S \\
\pi_{k s}^{2}\left(\sum_{v \in V} Y_{v k r}^{s}\right)=0 ; \quad \forall j \in N, s \in S \\
\pi_{i j s}^{3}\left(\sum_{r \in R} \sum_{v \in V} X_{v i j r}^{s}-\sum_{r \in R} \sum_{v \in V} X_{v j i r}^{s}\right)=0 ; \quad \forall(i, j) \in N, s \in S \\
\left.\pi_{r s}^{4}\left(\sum_{(i, j) \in N} \sum_{v \in V} X_{v i j r}^{s}+\sum_{k \in K} \sum_{v \in V} Y_{v k r}^{s}\right)-1\right)=0 ; \quad \forall r \in R, s \in S \\
\pi_{v r s}^{7}\left(\sum_{k \in K} Y_{v k r}^{s}-\sum_{(i, j) \in N} X_{v i j r}^{s}\right)=0 ; \quad \forall v \in V, r \in R, s \in S \\
\pi_{i j s}^{6}\left(p_{v i j}-\sum_{v \in V} \sum_{s \in S} E_{i v}^{s}+p_{v j i}\right)=0 ; \quad \forall(i, j) \in N, s \in S
\end{gathered}
$$




$$
\begin{gathered}
\pi_{k s}^{8}\left(\sum_{w \in W} Z_{k w}^{s}-\sum_{v \in V} \sum_{r \in R} Y_{v k r}^{s}\right)=0 ; \quad \forall k \in K, s \in S \\
\pi_{s}^{9}\left(\sum_{(i, j) \in N} \sum_{v \in V} \sum_{w \in W} \sum_{r \in R} X_{v i j r}^{s} c r_{w v i r} d_{i j r k}+\sum_{(i, j) \in N} \sum_{v \in V} \sum_{w \in W} \sum_{r \in R} \sum_{k \in K} Y_{v k r}^{s} c k_{w v r k} d_{i j r k}\right. \\
+\sum_{k \in K} \sum_{w \in W} Z_{k w}^{s} c h_{k w} q_{w}^{s}-\sum_{(i, j) \in N} \sum_{v \in V} \sum_{w \in W} \sum_{r \in R} \sum_{s^{\prime} \in S} \rho_{s} X_{v i j r}^{s^{\prime}} c r_{w v i r} d_{i j r k} \\
\left.-\sum_{(i, j) \in N} \sum_{v \in V} \sum_{w \in W} \sum_{r \in R} \sum_{k \in K} \sum_{s^{\prime} \in S} \rho_{s} Y_{v k r}^{s^{\prime}} c k_{w v r k} d_{i j r k}-\sum_{k \in K} \sum_{w \in W} \sum_{s^{\prime} \in S} \rho_{s} Z_{k w}^{s^{\prime}} c h_{k w} q_{w}^{s}+\theta_{s}^{\prime}\right) \\
=0 ; \quad \forall s \in S \\
\pi_{k w s}^{10}\left(\sum_{w \in W} \sum_{s \in S} U_{k w} Z_{k w}^{s}-\sum_{v \in V} \sum_{r \in R} q_{w}^{s} Y_{v k r}^{s}+\delta_{k s}\right)=0 ; \quad \forall k \in K, w \in W, s \in S \\
\pi_{s}^{11}\left(\theta_{s}^{\prime}\right)=0 ; \quad \forall(i, j) \in N, r \in R, v \in V, s \in S \\
\pi_{k s}^{12}\left(\delta_{k s}\right)=0 ; \quad \forall(i, j) \in N, r \in R, s \in S .
\end{gathered}
$$

Therefore, the single-level formula for collecting municipal waste, which is of the nonlinear mixed-integer programming type, is obtained and includes: the lower-level objective function (5); model constraints at the upper level of Eqs. (2), (3), (25), and (26); static constraints from Eqs. (42) to (48); the possible constraints of the primary problem

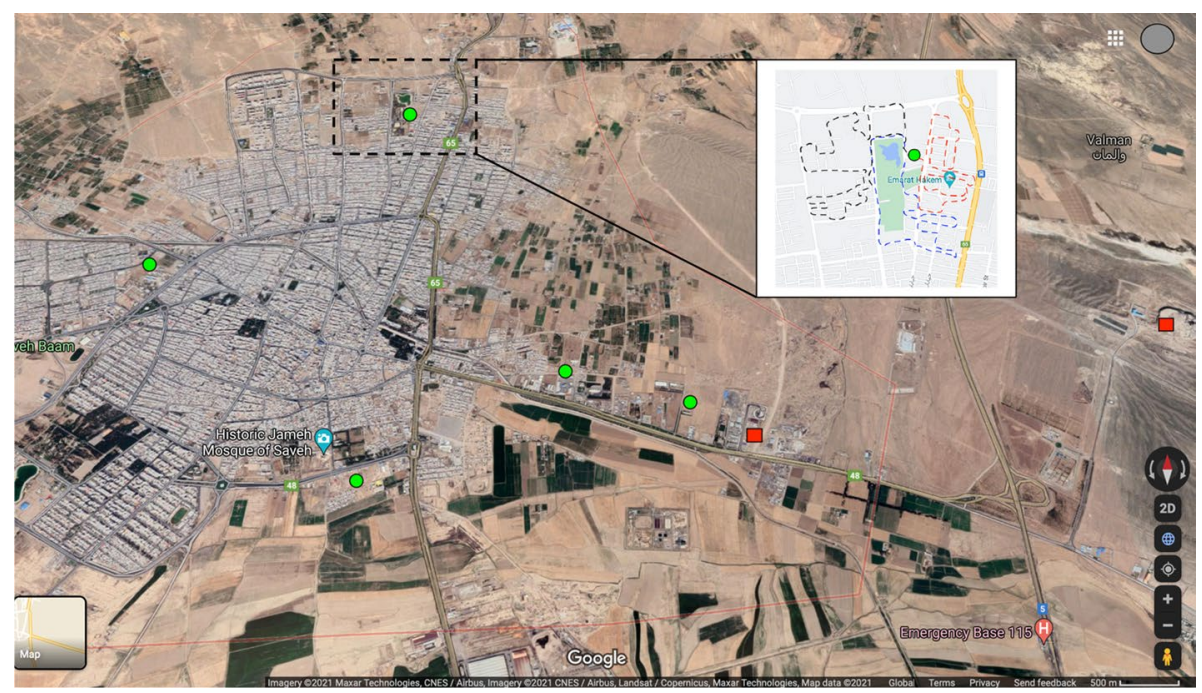

Fig. 3 Locations of waste recycling centers and waste separation centers in Saveh 
from Eqs. (7), (13), (14), and Eqs. (25) to (28); possible constraints of the dual problem $\left(\pi_{r s}^{4}, \pi_{v r s}^{7}, \pi_{k s}^{8}, \pi_{s}^{9}, \pi_{k w s}^{10}\right)$; and supplementary deficiency limits from Limits (49) to (60).

\section{Case study}

Saveh is located in central Iran with a population of 300,000 . Due to its industrial nature, up to 160 tons of municipal and industrial waste is produced daily in this city. Waste collection in this and other Iranian cities is the municipality's responsibility. This institute selects contractors to collect the generated waste by holding a public tender. The waste collection contractor in Saveh has a workforce of 120 and 45 vehicles that collect municipal waste at a certain time of the day and night and transfer it to separation centers. There are five waste separation centers in Saveh that separate recyclable waste, including paper, metal, glass, and plastic, from non-recyclable waste. After the separation operation, the recyclable waste is transferred to recycling centers outside the city and is recycled there. Figure 3 displays the position of five separation centers (green circles) and two waste recycling centers (red squares).

Contractors try to collect all the waste from the city daily at the minimum cost. In this study, we consider government support for contractors, which can reduce the total cost of the contractors. To support contractors and encourage them to recycle further, the government subsidizes the contractor for each unit (ton) of waste recycled. Figure 3 illustrates the movement routes of 3 vehicles with different colors to better understand the routes taken by the vehicles. These routes and the location of the bins are already known. The vehicles start their movement from the separation centers and return to the separation centers after traveling and filling the vehicle's capacity. This continues until all the waste in the city is collected.

Table 2 presents the information of 14 routes, the amount of waste collected along these routes, the route's length, and transportation costs related to waste collection and transfer to separation centers. The unit of waste is in kilograms, the distance in meters, and costs in US dollars.

It takes $67.52 \mathrm{~s}$ to solve the proposed model with real data and an accurate solution method by GAMS.23. In Tables 3 and 4, we present the results of the calculations based on three scenarios.

Table 2 Information on route costs and waste volume

\begin{tabular}{llllllll}
\hline Route no. & $\begin{array}{l}\text { The } \\
\text { volume of } \\
\text { wastes }\end{array}$ & $\begin{array}{l}\text { The transport } \\
\text { cost }\end{array}$ & Route length & Route no. $\begin{array}{l}\text { The } \\
\text { volume of } \\
\text { wastes }\end{array}$ & $\begin{array}{l}\text { The transport } \\
\text { cost }\end{array}$ & Route length \\
\hline 1 & 4485 & 10.25 & 12,524 & 8 & 4414 & 13.36 & 16,333 \\
2 & 3946 & 12.54 & 15,328 & 9 & 3962 & 14.93 & 18,245 \\
3 & 3499 & 9.02 & 11,024 & 10 & 3846 & 14.13 & 17,275 \\
4 & 4371 & 10.11 & 12,354 & 11 & 4419 & 14.88 & 18,187 \\
5 & 4627 & 7.25 & 8856 & 12 & 4559 & 16.79 & 20,524 \\
6 & 4341 & 8.49 & 10,374 & 13 & 4579 & 16.22 & 19,821 \\
7 & 4524 & 11.49 & 14,047 & 14 & 4679 & 17.11 & 20,916 \\
\hline
\end{tabular}




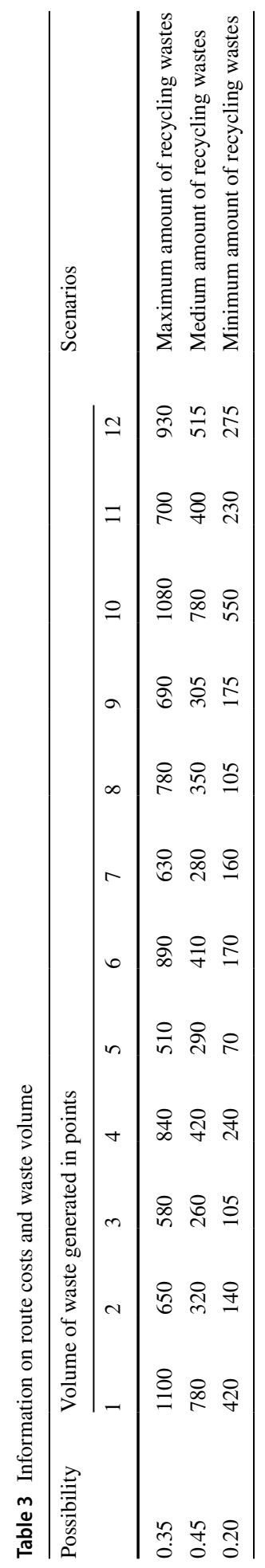




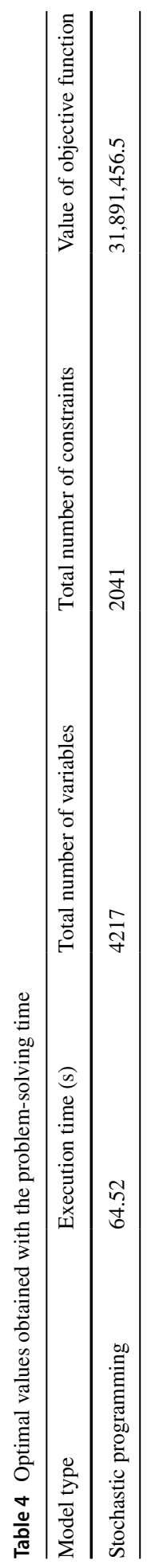


Table 5 Optimal values obtained for each level of the problem

\begin{tabular}{lllll}
\hline Problem no. & $\begin{array}{l}\text { The volume of } \\
\text { upper level }\end{array}$ & Changes rate $\%$ & $\begin{array}{l}\text { The volume of } \\
\text { upper level }\end{array}$ & Changes rate \% \\
\hline 1 & $34,411,692$ & 0.9724601 & $29,024,107$ & 0.0817757 \\
2 & $34,877,317$ & 0.98664963 & $28,884,558$ & 1.19220056 \\
3 & $34,939,931$ & 0.99820795 & $28,863,273$ & 2.74045802 \\
4 & $34,969,979$ & 0.99914075 & $28,803,257$ & 0.20793651 \\
5 & $34,994,075$ & 0.99931143 & $28,758,014$ & 1.03109656 \\
6 & $35,009,829$ & 0.99955001 & $28,721,651$ & 3.74846626 \\
7 & $35,135,189$ & 0.99643207 & $28,657,916$ & 1.45535714 \\
8 & $35,204,010$ & 0.99804508 & $28,641,938$ & 0.47257384 \\
9 & $35,231,175$ & 0.99922895 & $28,617,505$ & 0.37322835 \\
10 & $35,330,187$ & 0.99719752 & $28,452,726$ & 0.74354325 \\
\hline
\end{tabular}

Fig. 4 The results for the upper and lower levels and the bi-level model
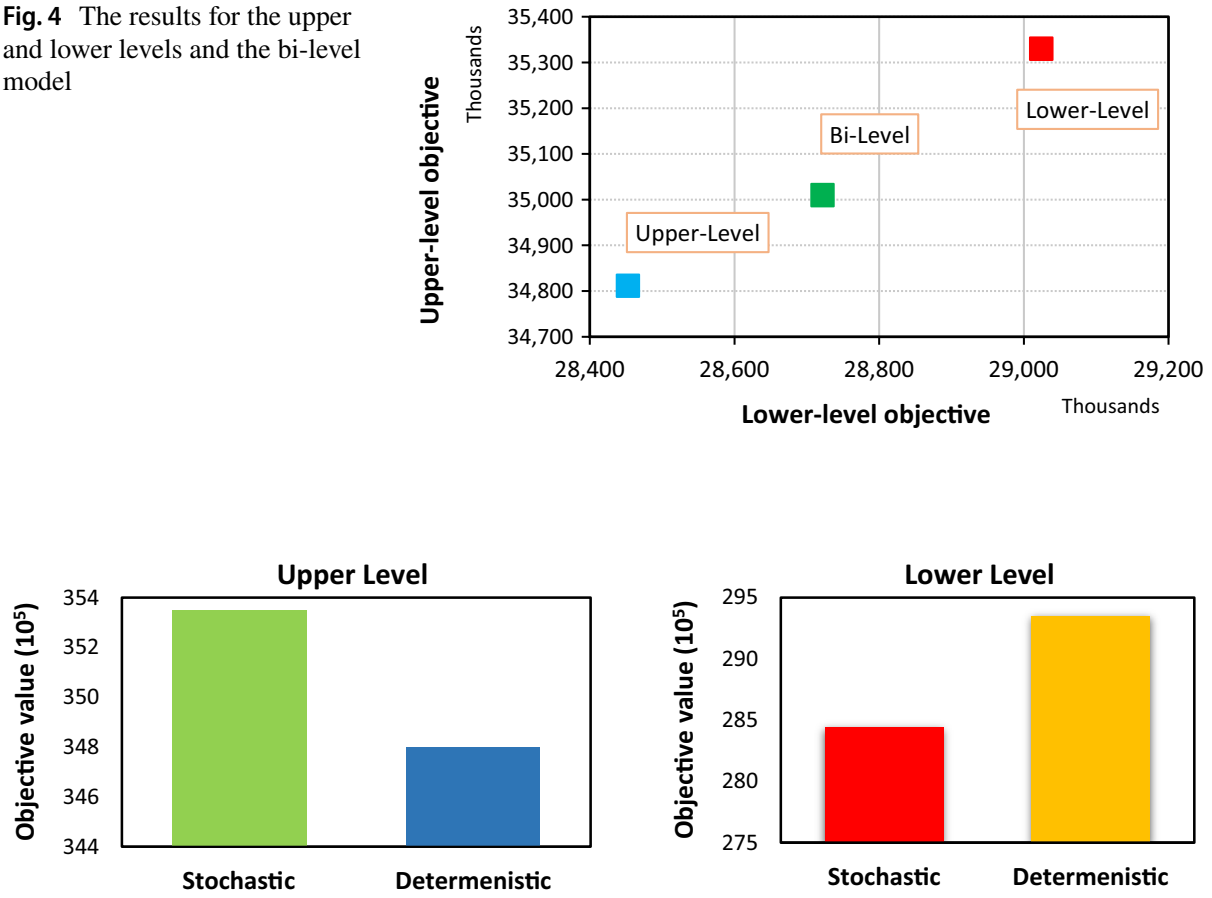

Fig. 5 The results of the objective function values

Table 5 lists the values obtained from 10 replicates of the problem related to the two levels of the proposed model. In addition to the obtained values related to government revenue and costs related to the collection and recycling of municipal waste, the amount of changes in each model solution is also demonstrated.

Figure 4 depicts the optimal values obtained for each level of the model and the bi-level model. Note that the solution of the bi-level model does not necessarily show the Pareto 
Fig. 6 The contractor's costs and the amount of waste generated

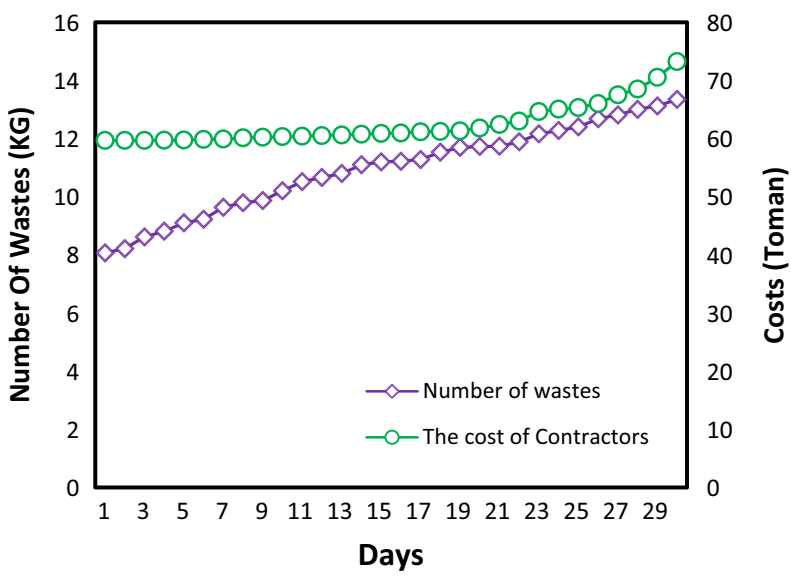

boundary. In other words, the solutions obtained in a two-objective model are not necessarily equal to the solutions obtained in a bi-level model. This is due to the bi-level nature of the model and the effectiveness of the model levels relative to each other (There are common limitations in the two levels). Based on Fig. 4, the optimal value of the model in the bi-level state tends toward the upper level of the model, suggesting the effect of the upper level on the optimal value.

Figure 5 displays the optimal values obtained for the two levels of the proposed model. According to the scenarios, the higher the amount of recyclable waste, the higher the government's profitability, while the contractors will receive the same amount of government subsidies. In the following, the effect of municipal waste production on the contractors' costs and the government's revenue is examined.

Figure 6 examines the data related to 30 days for the waste collected in Saveh. The contractors' costs are sensitive to the amount of waste generated, especially from the $19^{\text {th }}$ of the month onward. This is because the waste collected in the last ten days of the month has less recyclable waste, so the government subsidy has been significantly reduced. Waste theft (when people collect cartons, plastics, and other valuable waste from trash cans) explains the decrease in the amount of recyclable waste. Note that if

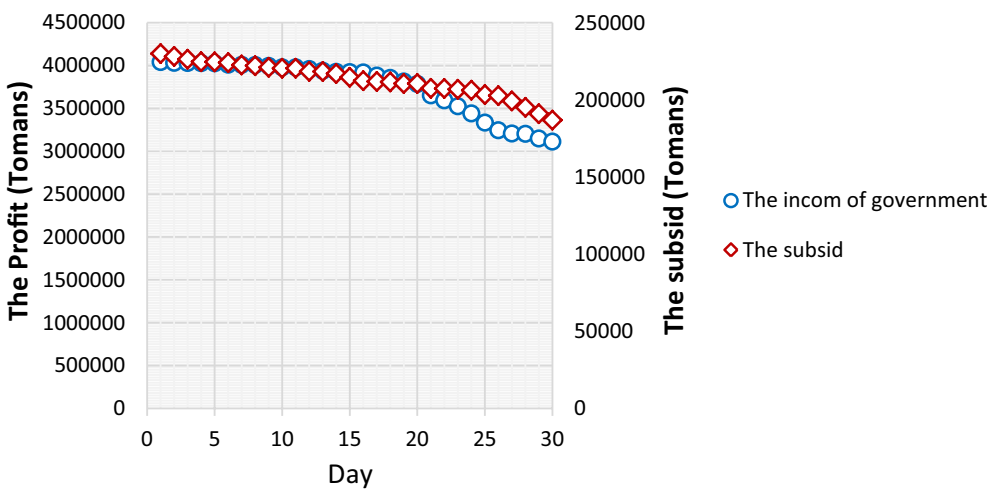

Fig. 7 The government revenue and subsidies paid 
Fig. 8 Sensitivity analysis for robustness

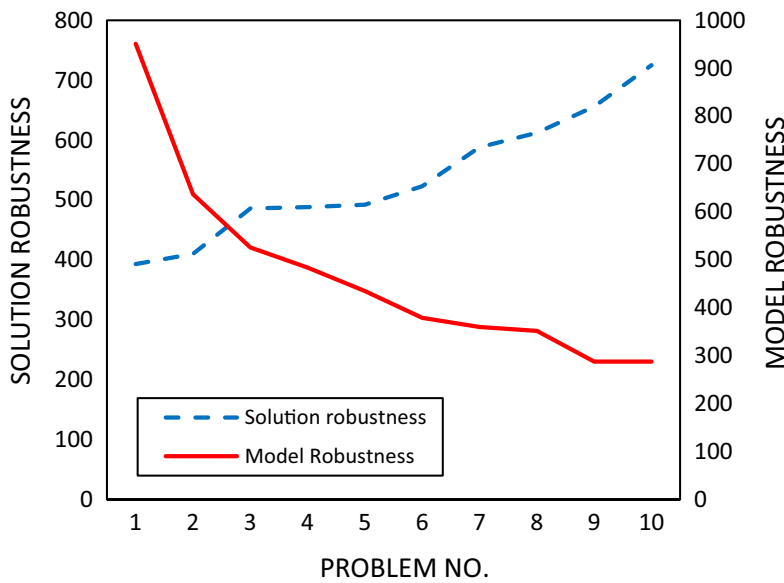

the content of waste increases, the contractors' costs will sharply increase; however, if the content of recyclable waste increases, the contractors will reimburse part of the costs by receiving government subsidies.

Figure 7 illustrates the government's revenue from municipal waste recycling over 30 days of the month. According to the data, the rising trend of government revenue in the first two decades of the month maintains its upward growth, but in the third decade of the month, the trend of government revenue is uniform with a tendency to decline. The reason for the increase in government revenue in the first 20 days was the presence of valuable waste in municipal waste. As the chart on subsidies shows, subsidies paid by the government have dropped dramatically in the third decade of the month due to the contractor's small recycling rate.

To ensure the results, the model and solution robustness must be evaluated. Robustness is assessed based on the weight of $\omega$ (indicating model feasibility) (Valizadeh, Aghdamigargari, et al., 2021; Valizadeh, Aickelin, et al., 2021; Valizadeh, Mozafari, et al., 2021; Valizadeh, Sayed Alizadeh, et al., 2021). As can be seen in Fig. 8, the model robustness shows different values based on the value of $\omega$. In fact, the different values obtained for the model robustness show that the control constraints of the robust model significantly affect

Fig. 9 Sensitivity analysis of the model based on the value of the objective function

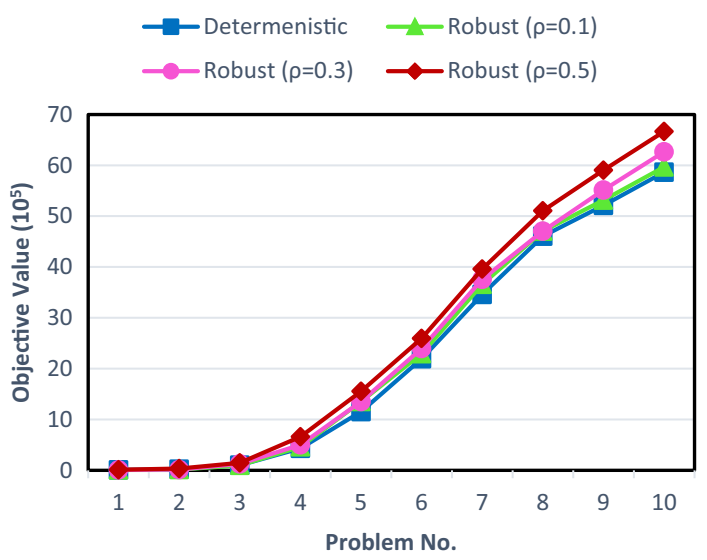


model performance. Figure 8 also shows that, as the weight of $\omega$ increases, the solution robustness increases. Nevertheless, by raising weight $\omega$, we see a downward trend in model robustness. In other words, for higher $\omega$ weights, although model robustness is possible, an elevation in the cost objective function occurs in each scenario. In addition, according to the analysis, the best value of $\omega$ for model robustness is approximately 920 . Meanwhile, the best value of $\omega$ for the solution robustness is approximately 700 .

Figure 9 demonstrates the government's and contractor's costs. The highest contractor cost is related to the transportation of waste between citizens and recycling centers. The government's policy of allocating subsidies to contractors as an incentive increases municipal waste recycling. However, with the increase in recycling rate, we observe the same degree of reduction in environmental pollutants. Figure 9 shows the sensitivity analysis of the model in both definite and robust states based on stochastic parameters.

Based on Fig. 9, the higher the stochastic parameter's value, the higher the objective function's value. In other words, the value of the objective function changes in different scenarios, but it shows the possible value in any case. Considering uncertain scenarios in urban waste collection planning and using a stochastic approach to deal with these uncertainties leads to beneficial management achievement. Exclusively, the definitiveness of mathematical models in applied problems diminishes the performance of these models. (i) Given that the amount of recycled waste in this study determines the amount of subsidy received by contractors, the amount of recyclable waste is considered indefinite in the proposed model. However, according to Fig. 5, the difference between the upper and lower levels of the objective function is about $50 \%$, which shows the huge impact of possible scenarios on the objective function's value, which is also discussed in Fig. 8. (ii) Based on Fig. 6, reducing waste recycling can increase the total cost by up to $20 \%$. Therefore, considering the government's supportive policy of allocating subsidies in exchange for temporary waste recycling can greatly help solve this problem. (iii) In addition, by examining Fig. 7, the payment of government subsidies is directly related to the amount of waste recycling. In other words, government subsidies play an effective role in motivating contractors to recycle more waste. Thus, the government can help the recycling cycle and make more use of recyclable materials by motivating and supporting the contractors. Furthermore, the contractors can follow the proposed model and receive the maximum government subsidy to reduce costs. Contractors can also minimize the costs of waste collection, transportation, and recycling by following the proposed model, which will significantly reduce the total cost by optimizing the capacity of vehicles and using appropriate communication routes.

\section{Conclusion}

Due to the exorbitant costs of producing raw materials such as glass, paper, plastics, and metals, waste recycling has always been a good solution to supply some of the required raw materials worldwide. Still, if inappropriate systems are employed for returning nonbiodegradable materials, the huge environmental pollution crisis is not unlikely. Therefore, governments should adopt various measures to support municipal waste collection contractors and those in charge of waste recycling. Herein, a bi-level model for efficient municipal waste management was proposed to address the bi-level concerns of those in charge simultaneously. In this research, the government was considered as the upper-level leader who, with a macro view of waste recycling, seeks to increase revenues from municipal waste recycling. On the other hand, contractors, who were, in fact, the executive body, 
were regarded as lower-level followers. The contractors' main concern was to reduce the total cost. We also considered the proposed model based on a scenario; three scenarios were regarded to evaluate the effect of uncertainty on the amount of municipal waste recycling. Due to the complexity of the randomly developed bi-level programming problem, the KKT condition was used as a solution to convert the bi-level problem into a one-level problem. The data from Saveh were used as a case study. The results of the problem in the case study showed the efficiency of the proposed method. By randomly generating different waste recycling rates, several computational analyses were performed, and essential management results were obtained.

Despite two contradictory levels of the problem (the upper level was the income maximization type and the lower level was the cost minimization model), the proposed model eventually achieved optimal values by considering various scenarios. We also prevented the production of hazardous environmental pollutants by maximizing recycling.

This study included the uncertainty of waste recycling. Future studies can consider uncertainty as related to other parameters, e.g., facility capacity and equipment reliability. With the new COVID-19 crisis, the uncertainty of household waste generation can also be considered. Like other scientific research, this research included some limitations, such as limited access to actual data, the non-cooperation of some organizations, and the impact of some of the unmeasurable hidden variables. In addition, this study considered just municipal waste. As further research, industrial and hospital wastes can be considered.

On the other hand, due to the dimensions of the problem in metropolitan cities (the amount of waste generated and many vehicles), it is necessary to use different methods to solve the problem, including meta-heuristic algorithms. According to the dimensions of the problem, future research can adopt meta-heuristic methods and algorithms. This study used data from and conducted the case study in Saveh; future studies can conduct case studies in large cities where waste management has become a major challenge.

\section{References}

Abdel-Basset, M., Mohamed, R., Sallam, K., \& Elhoseny, M. (2020). A novel decision-making model for sustainable supply chain finance under uncertainty environment. Journal of Cleaner Production, 269, 122324.

Agovino, M., Garofalo, A., \& Mariani, A. (2017). Separate waste collection in Italy: the role of socio-cultural factors and targets set by law. Environment, Development and Sustainability, 19(2), 589-605.

Ahi, P., \& Searcy, C. (2013). A comparative literature analysis of definitions for green and sustainable supply chain management. Journal of Cleaner Production, 52, 329-341.

Akbari, F., Valizadeh, J., \& Hafezalkotob, A. (2021). Robust cooperative planning of relief logistics operations under demand uncertainty: a case study on a possible earthquake in Tehran. International Journal of Systems Science: Operations \& Logistics, 22, 1-24.

Aydemir-Karadag, A. (2018). A profit-oriented mathematical model for hazardous waste locating-routing problem. Journal of Cleaner Production, 202, 213-225.

Babaee Tirkolaee, E., Mahdavi, I., \& Seyyed Esfahani, M. M. (2018). A robust periodic capacitated arc routing problem for urban waste collection considering drivers and crew's working time. Waste Management, 76, 138-146.

Baqeri, K., Mohammadi, E., \& Gilani, M. (2019). Multi objective project portfolio selection. Journal of Project Management, 4(4), 249-256.

Bautista, J., Fernández, E., Pereira, J., \& Nissan, C. (2008). Solving an urban waste collection problem using ant's heuristics. Computers \& Operations Research, 35(9), 3020-3033.

Bautista, J., \& Pereira, J. (2006). Modeling the problem of locating collection areas for urban waste management. An application to the metropolitan area of Barcelona. Omega, 34(6), 617-629. 
Bing, X., Keizer, M. D., Bloemhof-Ruwaard, J. M., \& van der Vorst, G. A. J. (2014). Vehicle routing for the eco-efficient collection of household plastic waste. Waste Management, 34(4), 719-729.

Boskovic, G., Jovicic, N., Jovanovic, S., \& Simovic, V. (2016). Calculating the costs of waste collection: a methodological proposal. Waste Management and Research, 34(8), 775-783.

Budzianowski, W. M. (2012). Sustainable biogas energy in Poland: prospects and challenges. Renewable and Sustainable Energy Reviews, 16(1), 342-349. https://doi.org/10.1016/j.rser.2011.07.161

Cao, J., Lu, B., Chen, Y., Zhang, X., Zhai, G., Zhou, G., Jiang, B., \& Schnoor, J. L. (2016). Extended producer responsibility system in China improves e-waste recycling: Government policies, enterprise, and public awareness. Renewable and Sustainable Energy Reviews, 62, 882-894.

Chalkias, A., \& Lasarid, E. (2009). Optimizing municipal solid waste collection using GIS. Waste Management, 47, 776-790.

Fetanat, A., Mofid, H., Mehrannia, M., \& Shafipour, Gh. (2019). Informing energy justice based decisionmaking framework for waste-to-energy technologies selection in sustainable waste management: a case of Iran. Journal of Cleaner Production, 228, 1377-1390.

González, J. F., Izquierdo, A. G., Commans, F., \& Carlos, M. (2021). Fuel-efficient driving in the context of urban waste-collection: a Spanish case study. Journal of Cleaner Production, 289, 125831.

Gopal, P. M., Sivaram, N. M., Barik, D. (2019). Chapter 7: paper industry wastes and energy generation from wastes, energy from toxic organic waste for heat and power generation (pp. 83-97).

Hannan, M. A., Akhtar, M., Begum, R. A., Basri, H., Hussain, A., \& Scavino, E. (2018). Capacitated vehicle-routing problem model for scheduled solid waste collection and route optimization using PSO algorithm. Waste Management, 71, 31-41.

Hansen, P., Jaumard, B., \& Savard, G. (1990). New branching and bounding rules for linear Bi-level programming, forthcoming in SIAM Journal on Scientific and Statistical Computing, 6, 25-29.

Haraguchi, M., Siddiqi, A., \& Narayanamurti, V. (2019). Stochastic cost-benefit analysis of urban waste-toenergy systems. Journal of Cleaner Production, 224, 751-765.

Hazra, A., Das, S., Majumdar, G., Naresh C. M., Banerjee, P. (2018). Plasma arc driven solid waste management: energy generation and green house gases (GHGs) mitigation, reference module in materials science and materials engineering. Encyclopedia of Renewable and Sustainable Materials, 3, 640-654.

$\mathrm{Hu}, \mathrm{C}$., Liu, X., Lu, J., \& Wang, C. (2020). Distributionally robust optimization for power trading of waste-to-energy plants under uncertainty. Applied Energy, V, 115509.

Hua, L., Shao, G., \& Zhao, J. (2017). A concise review of ecological risk assessment for urban ecosystem application associated with rapid urbanization processes. International Journal of Sustainable Development \& World Ecology, 24(3), 248-261.

Jabbarzadeh, A., Fahimnia, B., \& Seuring, S. (2014). Dynamic supply chain network design for the supply of blood in disasters: a robust model with real world application. Transportation Research Part E: Logistics and Transportation Review, 70, 225-244.

Jaunich, M. K., Levis, J. W., DeCarolis, J. F., Gaston, E. V., Barlaz, M. A., Bartelt-Hunt, S. L., Jones, E. G., Hauser, L., \& Jaikumar, R. (2016). Characterization of municipal solid waste collection operations. Resources, Conservation and Recycling, 114, 92-102.

Jin, Y., Tang, Z., Zhou, Q., Zeng, H., \& Mo, S. (2020). A government value compensation model of waste recycling in an industrial park: a game theory approach. Journal of Cleaner Production, 275, 122976.

Jorge, D., Antunes, A. P., Ramos, T. R. P., \& Barbosa-Póvoa, A. P. (2021). A hybrid metaheuristic for smart waste collection problems with workload concerns. Computers \& Operations Research, 137, 105518 .

Katinas, V., Marčiukaitis, M., Perednis, E., \& Dzenajavičienė, E. F. (2019). Analysis of biodegradable waste use for energy generation in Lithuania. Renewable and Sustainable Energy Reviews, 101, 559-567.

Kuo, R. J., Zulvia, F. E., \& Suryadi, K. (2012). Hybrid particle swarm optimization with genetic algorithm for solving capacitated vehicle routing problem with fuzzy demand - a case study on garbage collection system. Applied Mathematics and Computation, 219(5), 2574-2588. https://doi.org/10. 1016/j.amc.2012.08.092

Lou, X. F., Nair, J., \& Ho, G. (2013). Potential for energy generation from anaerobic digestion of food waste in Australia. Waste Management \& Research, 31(3), 283-294.

Manaf, L. A., Samah, M. A., \& Zukki, N. I. (2009). Municipal solid waste in Malaysia: practices and challenges. Waste Management, 29(11), 2902-2906.

Markov, I., Varone, S., \& Bierlaire, M. (2016). Integrating a heterogeneous fixed fleet and a flexible assignment of destination depots in the waste collection VRP with intermediate facilities. Transportation Research Part b: Methodological, 84, 256-273. 
Mello, V. M., Santos, D., Freitas, R., Yokoyama, L., \& Cammarota, M. C. (2018). Energy generation in the treatment of effluent from washing of municipal solid waste collection trucks. Sustainable Energy Technologies and Assessments, 30, 105-113.

Mulvey, J. M., Vanderbei, R. J., \& Zenios, S. A. (1995). Robust optimization of large-scale systems. Operations Research, 43(2), 264-281.

Musella, G., Agovino, M., Casaccia, M., \& Crociata, A. (2019). Evaluating waste collection management: the case of macro-areas and municipalities in Italy. Environment, Development and Sustainability, 21(6), 2857-2889.

Nayal, F. S., Mammadov, A., \& Ciliz, N. (2016). Environmental assessment of energy generation from agricultural and farm waste through anaerobic digestion. Journal of Environmental Management, 184(Part 2), 389-399.

Pérez-López, G., Prior, D., Zafra-Gómez, J. L., \& Plata-Díaz, A. M. (2016). Cost efficiency in municipal solid waste service delivery Alternative management forms in relation to local population size. European Journal of Operational Research, 255(2), 583-592.

Pouriani, S., Asadi-Gangraj, E., Paydar, M.M. (2019). A robust bi-level optimization modelling approach for municipal solid waste management; a real case study of Iran. Journal of Cleaner Production, 240, 118-125.

Rahman, M., \& Adnan, T. (2020). Risk management and risk management performance measurement in the construction projects of Finland. Journal of Project Management, 5(3), 167-178.

Ribeiro, E. M., Mambeli Barros, R., dos Tiago Filho, G. L. S., Santos, I. F., Sampaio, L., Santos, T., Silva, F., Silva, P. M., \& Freitas, J. (2018). Feasibility of biogas and energy generation from poultry manure in Brazil. Waste Management \& Research, 36(3), 221-235.

Richter, A., Ng, K. T. W., \& Pan, C. (2018). Effects of percent operating expenditure on Canadian nonhazardous waste diversion. Sustainable Cities and Society, 38, 420-428. https://doi.org/10.1016/j. scs.2018.01.026

Salazar-Adams, A. (2021). The efficiency of municipal solid waste collection in Mexico. Waste Management, 133, 71-79.

Sanjeevi, V., \& Shahabudeen, P. (2016). Optimal routing for efficient municipal solid waste transportation by using ArcGIS application in Chennai, India. Waste Management \& Research: the Journal for a Sustainable Circular Economy, 34(1), 11-21. https://doi.org/10.1177/0734242X15607430

Sbihi, A., \& Eglese, R. (2010). Combinatorial optimization and Green Logistics. Annals of Operations Research, 125, 159-175.

Soltan, S., \& Ashrafi, M. (2020). Predicting project duration and cost, and selecting the best action plan using statistical methods for earned value management. Journal of Project Management, 5(3), $157-166$.

Son, L. H., \& Louati, A. (2016). Modeling municipal solid waste collection: a generalized vehicle routing model with multiple transfer stations, gather sites and inhomogeneous vehicles in time windows. Waste Management, 52, 34-49.

Tavanayi, M., Hafezalkotob, A., \& Valizadeh, J. (2020). Cooperative cellular manufacturing system: a cooperative game theory approach. Scientia Iranica, 3, 32981. https://doi.org/10.24200/sci.2020.50315. 1629

Tseng, M. L., Wu, K. J., Hu, J., \& Wang, C. H. (2018). Decision-making model for sustainable supply chain finance under uncertainties. International Journal of Production Economics, 205, 30-36.

Valizadeh, J. (2020). A novel mathematical model for infectious waste collection and energy generation: case study of Kermanshah city. Management of Environmental Quality, 31(5), 1437-1453.

Valizadeh, J., Aickelin, U., \& Khorshidi, H. A. (2021b). A robust mathematical model for blood supply chain network using game theory. In $2021 \mathrm{~b}$ IEEE International Conference on Big Knowledge $(I C B K)$ (pp. 448-453). IEEE.

Valizadeh, J., Aghdamigargari, M., Jamali, A., Aickelin, U., Mohammadi, S., Khorshidi, H. A., \& Hafezalkotob, A. (2021). A hybrid mathematical modelling approach for energy generation from hazardous waste during the COVID-19 pandemic. Journal of Cleaner Production, 315, 128157.

Valizadeh, J., \& Mozafari, P. (2021). A novel cooperative model in the collection of infectious waste in COVID-19 pandemic. Journal of Modelling in Management. https://doi.org/10.1108/ JM2-07-2020-0189

Valizadeh, J., Mozafari, P., \& Hafezalkotob, A. (2021). Municipal waste management and electrical energy generation from solid waste: a mathematical programming approach. Journal of Modelling in Management. https://doi.org/10.1108/JM2-07-2020-0193

Valizadeh, J., Sayed Alizadeh, S., Hafezalkotob, A., \& Mozafari, P. (2021). Hazardous infectious waste collection and government aid distribution during COVID-19: A robust mathematical leader-follower model approach. Sustainable Cities and Society, 69, 102814. 
Zhang, J., Mao, L., Nithya, K., Loh, K. C., Dai, Y., He, Y., \& Tong, Y. W. (2019). Optimizing mixing strategy to improve the performance of an anaerobic digestion waste-to-energy system for energy recovery from food waste. Applied Energy, 249, 28-36.

Zhang, Q., Zhao, X., Lu, H., Ni, T., \& Li, Y. (2017). Waste energy recovery and energy efficiency improvement in China's iron and steel industry. Applied Energy, 191, 502-520.

Zhang, X., \& Huang, G. (2014). Municipal solid waste management planning considering greenhouse gas emission trading under fuzzy environment. Journal of Environmental Management, 135, 11-18.

Zhao, N., \& You, F. (2021). Food-energy-water-waste nexus systems optimization for New York State under the COVID-19 pandemic to alleviate health and environmental concerns. Applied Energy, 282(Part A), 116181.

Publisher's Note Springer Nature remains neutral with regard to jurisdictional claims in published maps and institutional affiliations. 